\title{
Epidemiologic Survey of Kawasaki Disease in Jilin from 1999 Through 2008
}

\author{
Xiaomei Zhang $\cdot$ Zhen Zhang $\cdot$ Shicheng Liu $\cdot$ \\ Jinghui Sun
}

Received: 24 May 2011/Accepted: 12 September 2011/Published online: 1 October 2011

(C) The Author(s) 2011. This article is published with open access at Springerlink.com

\begin{abstract}
The epidemiologic pictures of Kawasaki disease (KD) in Jilin Province of China is still not clear. We sent a questionnaire form and diagnostic guidelines for KD to the province's 32 hospitals above the county and city level with pediatric in-patients. All patients with KD diagnosed during January 1999 through December 2008 were recruited in this survey. The incidence of KD was 1.39 to $11.07(5.26 \pm 3.97)$ per 100,000 children under the age of 5 years between 1999 and 2008 . The ratio of male to female was 1.96 to 1 . Ages at onset ranged from 58 days to 14 years. Patients under 5 years of age accounted of $88.73 \%$. The disease occurred throughout the year, but it occurred more frequently in May to July and November. The most common cardiac abnormality was coronary artery dilatation $(49.5 \%)$. Age at onset and hypoalbuminemia $(<30 \mathrm{~g} / \mathrm{l})$ were selected for multivariate logistic regression equation. In conclusion, incidences of KD increased in Jilin Province. Age and gender distribution shared similarities with previous reports, and the seasonal distribution was different. Age and lower serum albumin were the most important risk factors of coronary arterial lesions (CAL) in KD. In addition, patients treated with steroids also had a possible heightened risk of contracting CAL.
\end{abstract}

Keywords Kawasaki disease - Epidemiology · Incidence $\cdot$ Coronary arterial lesions · Jilin Province . China

This study is conducted on behalf of the Jilin Province Kawasaki Disease Research Group.

X. Zhang $\cdot$ Z. Zhang $\cdot$ S. Liu $\cdot$ J. Sun $(\bowtie)$

Department of Pediatrics, The First Hospital of Jilin University,

71 Xin Min Street, Changchun 130021, Jilin, China

e-mail: sunjinghui2558@126.com
Kawasaki disease (KD), or mucocutaneuous lymph node syndrome, was first reported by Dr. Tomisaku Kawasaki of Japan in 1967. Currently, KD is known to have a worldwide distribution as a common disease predominantly affecting children younger than 5 years. Kawasaki disease is the most common cause of multisystem vasculitis in children. The vessels most commonly damaged are the coronary arteries, making $\mathrm{KD}$ the number one cause of acquired heart disease in childhood. Therefore, KD has become an important research topic in the field of pediatric cardiology. An epidemiologic survey of children hospitalized with KD across Jilin Province was conducted. This survey aimed to understand the incidence and epidemiologic features of $\mathrm{KD}$, to explore its causes and impact factors, and to provide a scientific basis for early diagnosis and treatment. The results are reported in the following sections.

\section{Methods}

Case Ascertainment and Quality Control

Sets including a survey questionnaire form and diagnostic guidelines for $\mathrm{KD}$ were sent to 32 hospitals above the county and city level with pediatric in-patients in Jilin Province, China. Patients with KD were identified by the discharge diagnosis code in the records. Pediatricians were asked to review the medical records and report all patients with KD during the 10-year span from 1 January 1999 through 31 December 2008.

Training and preparation for the survey were based on the network of the KD research group established in nine districts of Jilin Province. All the pediatricians who participated in the survey were pediatric cardiologists or 
senior pediatricians. Two senior pediatricians were designated to ensure investigators' compliance with the study protocol. Additionally, after all survey questionnaires were initially collected, the forms were further verified by two senior cardiologists in our Pediatric Institute to prevent anomalies and human error. This collected information then was pooled into a larger KD database.

\section{Definition and Recruitment Criteria}

The fifth revised edition of diagnostic criteria for KD issued by the Japan Kawasaki Disease Research Committee at the 7th International Kawasaki Disease Symposium in 2002 was adopted. Cases were included in the survey if the patients had at least five of the following six clinical manifestations or at least four signs together with coronary abnormalities documented by echocardiography or coronary angiography: (1) fever persisting 5 days or longer (including cases with fever that subsided before day 5 in response to therapy), (2) bilateral conjunctival congestion, (3) changes in the lips and the oral cavity such as reddening of lips, strawberry tongue, and diffuse congestion of oral and pharyngeal mucosa, (4) polymorphous exanthema, (5) changes in the peripheral extremities such as reddening of the palms and soles, indurative edema at the initial stage, or membranous desquamation from the fingertips at the convalescent stage; and (6) acute nonpurulent cervical lymphadenopathy.

In addition, the cases of incomplete $\mathrm{KD}$, diagnosed with reference to the guidelines for incomplete KD made by the American Academy of Pediatrics (AAP) and the American Heart Association (AHA) in 2004 also were included in this investigation. Patients who did not fulfill the aforementioned criteria or who were not in Jilin Province long enough also were excluded.

\section{Survey Implementation}

Basic patient information was recorded on the questionnaire form. This information included age, gender, ethnic background and location, date of KD onset, date of diagnosis, days from onset to hospital visit, clinical signs and symptoms, cardiac and extracardiac manifestations, laboratory examination, echocardiogram (echo) results, prognosis and treatment, outcome, cardiac sequelae, and recurrence.

\section{Analysis of Risk Factors for Coronary Artery Lesions}

The potential risk factors for coronary artery lesion (CAL) were analyzed including age at onset, sex, month at onset, fever lasting 10 days or longer, C-reactive protein $(>30 \mathrm{mg} / \mathrm{l})$, erythrocyte sedimentation rate $(\geq 40 \mathrm{~mm} / \mathrm{h})$, alanine aminotransferase $(\geq 40 \mathrm{U} / \mathrm{l})$, white blood cell count $\left(\geq 12 \times 10^{9} / 1\right)$, hemoglobin $(<90 \mathrm{~g} / \mathrm{l})$, blood platelet count $\left(\geq 450 \times 10^{9} / 1\right)$, creatine kinase $(\geq 25 \mathrm{U} / \mathrm{l})$, serum albumin level $(<30 \mathrm{~g} / \mathrm{l})$, and administration of steroids for KD.

\section{Statistical Analysis}

Parametric data are expressed as mean \pm standard deviation. Nonparametric analysis was performed using the Pearson chi-square test. Differences in means were compared by $t$ test or one-way analysis of variance (ANOVA). Logistic regression analysis was performed to analyze the risk factors for CAL. The partial regression coefficient (B), standardized partial regression coefficient (SE), odds ratio $(\mathrm{OR})$, and $95 \%$ confidence interval $(95 \% \mathrm{CI})$ were reported. A $P$ value less than 0.05 was considered statistically significant. All analyses were performed using IBM SPSS statistics 18 (IBM, New York, United States).

\section{Results}

Response to the Survey

The survey forms were returned at a rate of $93.75 \%$. From the 32 hospitals in 9 districts, $603 \mathrm{KD}$ cases were reported. During the censorship and quality control, 26 cases were excluded because they did not fulfill the aforementioned criteria. The remaining 577 cases of KD were enrolled in our study population. Of the 577 cases, $480(83.2 \%)$ were typical $\mathrm{KD}$ according to the fifth revised edition of diagnostic criteria for $\mathrm{KD}$, and the remaining 97 cases $(16.8 \%)$ were incomplete $\mathrm{KD}$ according to the guidelines for incomplete KD formulated by AAP and AHA. Furthermore, 512 of the patients $(88.7 \%)$ were younger than 5 years, and the remaining 65 patients were older than 5 years.

\section{Incidence of KD}

The incidence rates for KD diagnoses varied significantly from 1999 through 2008. Based on the Statistical Yearbook data for Jilin Province, the average annual incidence of diagnosed KD tended to increase by years (Table 1). The 577 patients consisted of $382(66.2 \%)$ males and 195 $(33.8 \%)$ females, giving a gender ratio of 1.96:1. Four minority groups were represented by 50 cases $(8.7 \%)$ including 43 Korean cases, 4 Manchu cases, 2 Hui cases, and 1 Mongolian case. These groups were dispersed throughout the surveyed population.

\section{Age Distribution at Onset of KD}

The age at onset of $\mathrm{KD}$, derived from the date of the first diagnosis minus the date of birth, ranged from 58 days to 
Table 1 Incidence of Kawasaki disease (KD) in Jilin Province China from 1999 through 2008 (per 100,000 children younger than 5 years)

\begin{tabular}{|c|c|c|c|c|c|c|c|c|c|}
\hline \multirow[t]{2}{*}{ Calendar year } & \multicolumn{3}{|l|}{ Males } & \multicolumn{3}{|c|}{ Females } & \multicolumn{3}{|l|}{ Total } \\
\hline & $\begin{array}{l}\text { No. of } \\
\text { KD } \\
\text { cases }\end{array}$ & Population & $\begin{array}{l}\text { KD annual } \\
\text { incidence per } \\
100,000 \text { year }\end{array}$ & $\begin{array}{l}\text { No. of } \\
\text { KD } \\
\text { cases }\end{array}$ & Population & $\begin{array}{l}\text { KD annual } \\
\text { incidence per } \\
100,000 \text { year }\end{array}$ & $\begin{array}{l}\text { No. of } \\
\text { KD } \\
\text { cases }\end{array}$ & Population & $\begin{array}{l}\text { KD annual } \\
\text { incidence per } \\
100,000 \text { year }\end{array}$ \\
\hline 1999 & 12 & 676,185 & 1.77 & 6 & 614,714 & 0.98 & 18 & $1,290,900$ & 1.39 \\
\hline 2000 & 7 & 673,776 & 1.04 & 5 & 612,523 & 0.82 & 12 & $1,286,300$ & 0.93 \\
\hline 2001 & 18 & 660,628 & 2.72 & 9 & 600,571 & 1.50 & 27 & $1,261,200$ & 2.14 \\
\hline 2002 & 19 & 642,661 & 2.96 & 9 & 584,238 & 1.54 & 28 & $1,226,900$ & 2.28 \\
\hline 2003 & 24 & 610,133 & 3.93 & 15 & 554,666 & 2.70 & 39 & $1,164,800$ & 3.35 \\
\hline 2004 & 35 & 559,428 & 6.26 & 19 & 508,571 & 3.74 & 54 & $1,068,000$ & 4.87 \\
\hline 2005 & 48 & 559,428 & 8.58 & 23 & 508,571 & 4.52 & 71 & $1,068,000$ & 6.65 \\
\hline 2006 & 58 & 546,333 & 10.62 & 29 & 496,666 & 5.84 & 87 & $1,043,000$ & 8.34 \\
\hline 2007 & 80 & 536,800 & 14.90 & 39 & 488,000 & 7.99 & 119 & $1,024,800$ & 11.61 \\
\hline 2008 & 81 & 529885 & 15.29 & 41 & 481,714 & 8.51 & 122 & $1,011,600$ & 11.07 \\
\hline Total & 382 & $5,995,257$ & 66.2 & 195 & $5,450,234$ & 33.8 & 577 & $11,445,500$ & 5.04 \\
\hline
\end{tabular}

14 years (mean, $2.67 \pm 2.37$ years). The patients younger than 1 year accounted for 225 cases (39\%), and the patients younger than 5 years accounted for 512 cases (88.7\%). One incidence peak occurred at the age of 1 year. The distribution of ages at KD onset is shown in Fig. 1.

\section{Seasonal Distribution of KD}

As shown in Fig. 2, during the 10-year period, the onset of KD occurred more frequently from May (62 cases, 10.7\%) to July (66 cases, $11.4 \%$ ) and November (70 cases, $12.1 \%$ ), whereas it occurred relatively less frequently in February (21 cases, 3.6\%). One peak occurred for the boys in June (48 cases, $8.3 \%$ ), whereas the peak for the girls occurred in November (30 cases, $5.2 \%$ ).

\section{Clinical Manifestations of KD}

Among the main clinical manifestations mentioned in the diagnostic criteria for $\mathrm{KD}$, the most frequent was fever persisting for 5 days or longer (574 cases, $99.5 \%$ ), followed by changes in the lips and the oral cavity ( 523 cases, $90.6 \%$ ), changes in peripheral extremities at the initial stage or the convalescent stage (490 cases, $84.8 \%$ ), bilateral conjunctival congestion (439 cases, $76.1 \%$ ), polymorphous exanthema (438 cases, $75.9 \%$ ), and acute nonpurulent cervical lymphadenopathy (400 cases, 69.3\%). Additional manifestations included crissum desquamate (200 cases, $32.9 \%$ ) and erythema (10 cases, 1.7\%) at the Calmette-Guérin Bacillus inoculation site. The other systems involved included the respiratory system (325 cases,
Fig. 1 The distribution of age at onset of Kawasaki disease in Jilin Provence, China from 1999 through 2008

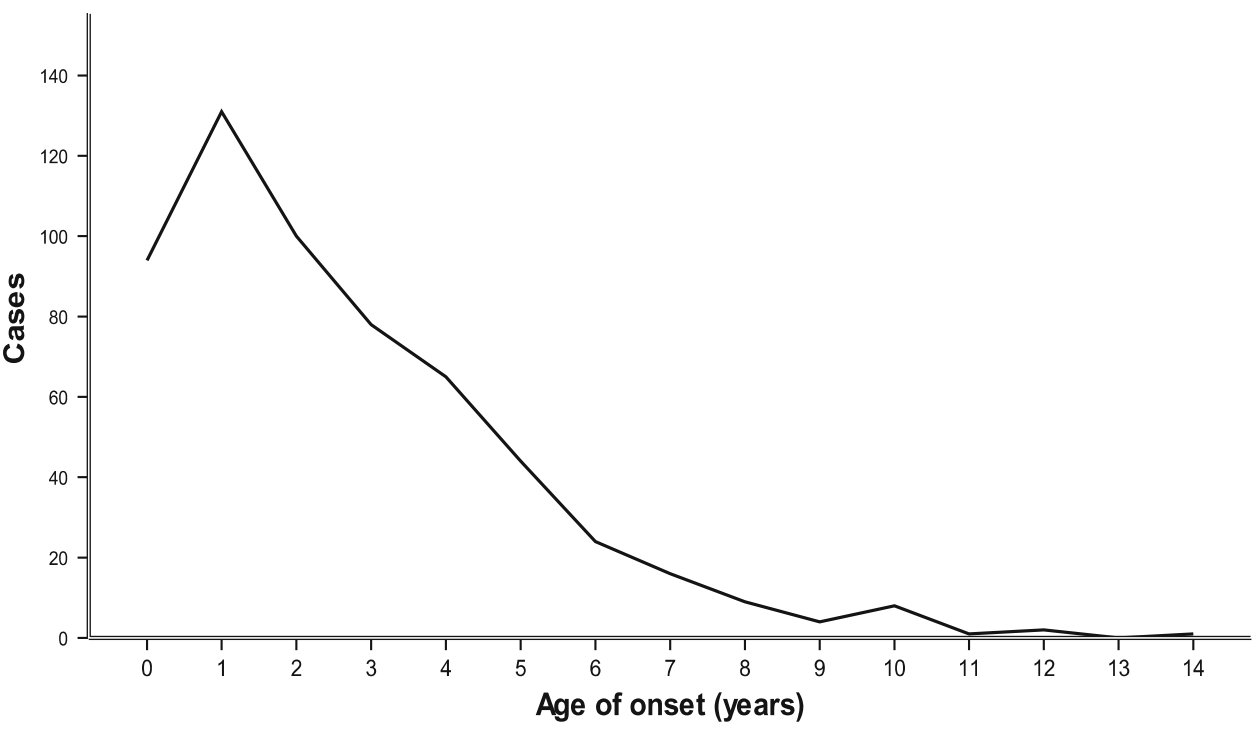


Fig. 2 The seasonal distribution of Kawasaki disease in Jilin Provence, China from 1999 through 2008

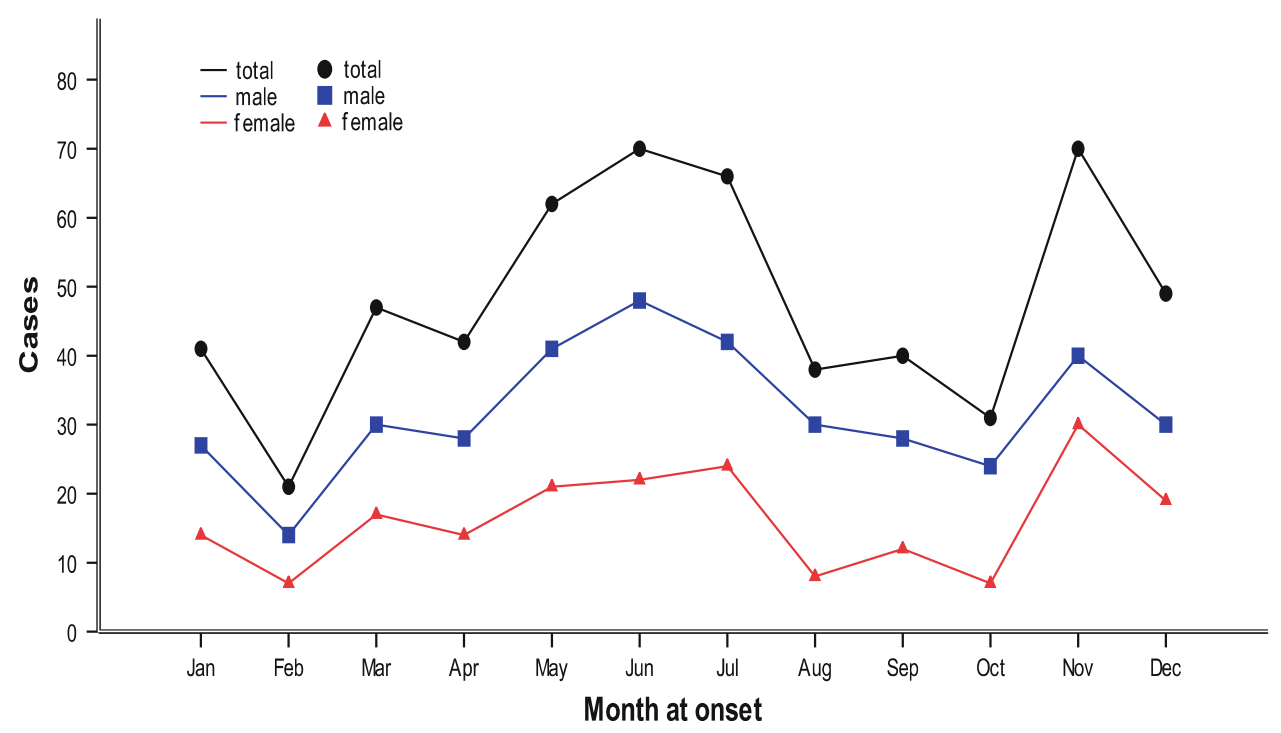

56.3\%), the digestive system (142 cases, 24.6\%), the hematologic system (90 cases, 15.6\%), the urinary system (23 cases, $3.9 \%$ ), and the joints of extremities (15 cases, $2.6 \%)$.

The main clinical manifestations of KD were shown in Table 2. The acute and subacute stages of the disease caused no fatality. Three patients $(0.5 \%)$ had a second onset of the disease in 3 months to 3 years after the first onset. No specific factors were found to be associated with recurrence in our survey.

\section{Echocardiographic Findings of KD}

Echocardiographic examinations were carried out in 553 cases (95.8\%) within 1 month after the onset of KD. Among these, 350 cases $(63.3 \%)$ were found to be abnormal, including coronary artery ectasia (274 cases, $49.5 \%$ ), coronary artery stenosis (74 cases, $13.4 \%$ ), coronary artery aneurysm ( 2 cases, $0.36 \%$ ), pericardial effusion (5 cases, $0.9 \%)$, left ventricular enlargement (6 cases, $1.1 \%)$, left artery coronary mural thrombus ( 2 cases, $0.36 \%$ ), and right artery coronary mural thrombus ( 1 case, $0.18 \%$ ). Different

Table 2 The main clinical manifestations of the 577 patients with Kawasaki disease in Jilin Provence, China from 1999 through 2008

\begin{tabular}{lll}
\hline Clinical symptoms & Cases & $\%$ \\
\hline Fever & 574 & 99.5 \\
Oral and lip changes & 523 & 90.6 \\
Extremities desquamate & 490 & 84.8 \\
Bilateral conjunctival congestion & 439 & 76.1 \\
Rashes & 438 & 75.9 \\
Lymphadenopathy & 400 & 69.3 \\
\hline
\end{tabular}

cardiac abnormities could be found in one patient simultaneously.

Administration of Intravenous Immunoglobulin

Infusion of intravenous immunoglobulin (IVIG) (human freeze-dried low-pH intravenous gammaglobulin; Biochemical Product Institute of Ministry of Public Health, Chengdu, China) was administrated to 512 patients $(88.7 \%)$ within 1 month after KD onset. Although most patients were administered IVIG within 2 weeks after disease onset, atypical clinical manifestations of the disease complicated diagnosis. This caused a delay in the IVIG treatment for some patients. Others were delayed due to possible economic constraints.

The regimen of $400 \mathrm{mg} / \mathrm{kg} /$ day for 5 consecutive days was used in 230 cases $(39.9 \%), 1,000 \mathrm{mg} / \mathrm{kg}$ once in 19 cases $(3.3 \%), 1,000 \mathrm{mg} / \mathrm{kg}$ twice in 148 cases $(25.7 \%)$, $2,000 \mathrm{mg} / \mathrm{kg}$ once in 15 cases $(2.6 \%)$, irregular amount in 99 cases $(17.2 \%)$, and no response in 1 case $(0.2 \%)$. Among these regimens, $400 \mathrm{mg} / \mathrm{kg} /$ day for 5 consecutive days or $1,000 \mathrm{mg} / \mathrm{kg}$ twice was adopted most often. No adverse effect due to the administration of IVIG was found in the series. The regimens of IVIG administration are shown in Fig. 3.

\section{Coronary Artery Lesions and Their Risk Factors}

Data on cardiac findings based on echocardiography were available for 553 patients. Cardiac lesions of KD were the most frequent at an age younger than 5 years (90.1\%), with the peak at 1 year, accounting for $45.2 \%$ of the patients younger than 1 year. Significant differences were found between younger and older children, with CAL seen more frequently in younger children (age, $2.7 \pm 2.4$ years; 
Fig. 3 The dosage of Intravenous immunoglobulin for Kawasaki disease by calendar year in Jilin Province, China from 1999 through 2008

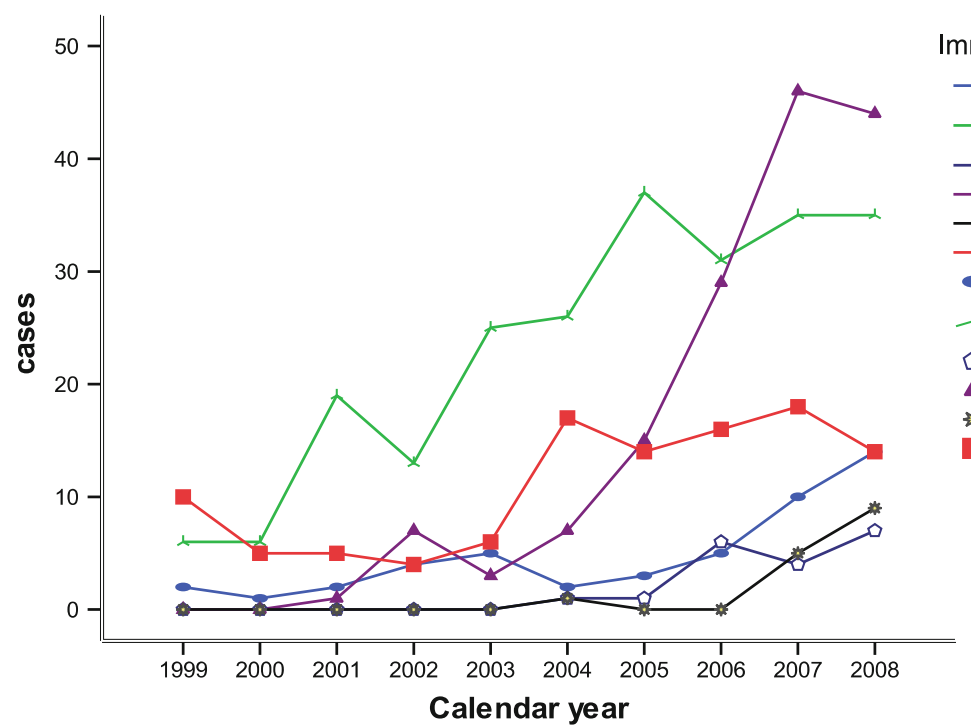

Immunoglobulin regimen

- Without usage

_ $400 \mathrm{mg} / \mathrm{kg}$. d concecutive 5

days

- $1000 \mathrm{mg} / \mathrm{kg}$ once

- $1000 \mathrm{mg} / \mathrm{kg}$ twice

- $2000 \mathrm{mg} / \mathrm{kg}$ once

- other usage

- Without usage

ᄉ $400 \mathrm{mg} / \mathrm{kg}$.d concecutive 5

days

(1000 $\mathrm{mg} / \mathrm{kg}$ once

- $1000 \mathrm{mg} / \mathrm{kg}$ twice

* $2000 \mathrm{mg} / \mathrm{kg}$ once

other usage $t=19.872 ; P=0.000)$. Comparison of incomplete $\mathrm{KD}$ with complete KD showed significant differences in the occurrence of CAL, with an increased frequency in cases of incomplete KD (49.5\% [46/93] vs 66.1\% [304/460]; $\left.\chi^{2}=9.202 ; P<0.05\right)$. As to the proportion of CAL, no significant differences were found between the boys and the girls $(61.3 \% \quad[225 / 367]$ vs $67.2 \% \quad[125 / 186]$; $\left.\chi^{2}=1.847 ; P>0.05\right)$.

Our data showed significant differences between the KD group that had administration of IVIG in CAL as diagnosed by echocardiography and the group that did not $(t=$ $-18.570 ; P=0.000)$. In our study, $2.4 \%$ of the patients had cardiac sequelae. The most important cardiac sequela was coronary artery ectasia, which accounted for $78.6 \%$ of the cases, followed by coronary artery aneurysm $(14.3 \%)$ and coronary artery stenosis $(7.1 \%)$. The proportion of cardiac sequelae was higher among the infants, with $50 \%$ occurring among infants younger than 1 year.

Single-factor analysis of the factors relevant to CAL was conducted with a focus on patient age, sex, month contracted, duration of fever ( $\geq 10$ days), white blood cell count $\left(\geq 12 \times 10^{9} / 1\right)$, hemoglobin $(<90 \mathrm{~g} / \mathrm{l})$, blood platelet count $\left(\geq 450 \times 10^{9} / 1\right)$, erythrocyte sedimentation rate $(\geq 40 \mathrm{~mm} /$ h), C-reactive protein $(>30 \mathrm{mg} / \mathrm{l})$, alanine aminotransferase $(\geq 40 \mathrm{U} / \mathrm{l})$, creatine kinase (CK-MB) $(\geq 25 \mathrm{U} / \mathrm{l})$, and serum albumin $(<30 \mathrm{~g} / \mathrm{l})$. The results indicated that age at onset and lower serum albumin were associated with CAL. Although $P$ values approximating 0.05 for fever persisting days for 10 days or longer and blood platelet count of $450 \times 10^{9} / 1$ or more may have been relevant to CAL, no significant differences were found. The single-factor analysis of the factors relevant to CAL is shown in Table 3.

We conducted nonconditional multivariate logistic regression analysis for a single factor that related to $\mathrm{CAL}$ in $\mathrm{KD}$. The results showed that age at onset and
Table 3 Single-factor analysis of the relevant factors for coronary artery lesion (CAL) among the 553 patients with Kawasaki disease in Jilin Province, China from 1999 through 2008

\begin{tabular}{lrl}
\hline Observed indicator & $\chi^{2}$ & $P$ value \\
\hline Age & 11.474 & $0.001^{\mathrm{a}}$ \\
Sex & 1.631 & 0.202 \\
Incidence for the month & 1.697 & 0.193 \\
Fever persisting $\geq 10$ days & 3.557 & 0.059 \\
White blood cell count $\geq 12 \times 10^{9} / 1$ & 0.829 & 0.363 \\
Hemoglobin $<90 \mathrm{~g} / 1$ & 1.332 & 0.248 \\
Blood platelet count $\geq 450 \times 10^{9} / 1$ & 3.229 & 0.072 \\
Erythrocyte sedimentation rate $\geq 40 \mathrm{~mm} / \mathrm{h}$ & 2.262 & 0.133 \\
C-reactive protein $>30 \mathrm{mg} / \mathrm{l}$ & 0.015 & 0.903 \\
Alanine aminotransferase $\geq 40 \mathrm{U} / 1$ & 0.963 & 0.326 \\
Creatine kinase $\geq 25 \mathrm{U} / 1$ & 0.321 & 0.571 \\
Hypoalbuminemia $<30 \mathrm{~g} / \mathrm{l}$ & 7.037 & $0.008^{\mathrm{a}}$ \\
\hline
\end{tabular}

${ }^{\text {a }} P<0.05$. Observed indicators were associated with CAL

hypoalbuminemia $(<30 \mathrm{~g} / \mathrm{l})$ were selected for the multivariate logistic regression equation, indicating that age at onset and hypoalbuminemia were risk factors for $\mathrm{KD}$ complicated by CAL (Table 4). We obtained the following regression equation:

$y=-0.118 X 1+0.459 X 2-1.646$.

The findings showed that administration of steroids was related to CAL. According to our data, in addition to 13 cases for which it was not clear whether steroids were administrated before other treatment, the relation between the incidence of CAL and the administration of steroids was studied in the remaining 520 patients. The results showed significant differences, with the CAL incidence significantly higher among the patients with steroids than among the other patients $(18.8 \%$ [64/341] vs $8.9 \%$ [16/ 179]; $\left.\chi^{2}=8.71 ; P<0.005\right)$. 
Table 4 Nonconditional multivariate logistic regression analysis of Kawasaki disease (KD) complicated by coronary artery lesion (CAL) among the 553 patients with Kawasaki disease in Jilin Province, China from 1999 through 2008

\begin{tabular}{|c|c|c|c|c|c|c|c|}
\hline \multirow[t]{2}{*}{ Observed indicator } & \multirow[t]{2}{*}{$\mathrm{B}$} & \multirow[t]{2}{*}{ SE } & \multirow[t]{2}{*}{ Wald $\chi^{2}$} & \multirow[t]{2}{*}{$P$ value } & \multirow[t]{2}{*}{ OR } & \multicolumn{2}{|c|}{$95 \%$ CI for EXP (B) } \\
\hline & & & & & & Lower & Upper \\
\hline Age at onset $(X 1)$ & -0.118 & 0.037 & 9.999 & $0.002^{\mathrm{a}}$ & 1.125 & 1.046 & 1.211 \\
\hline Hypoalbuminemia $(<30 \mathrm{~g} / 1)(X 2)$ & 0.459 & 0.196 & 5.523 & $0.019^{\mathrm{a}}$ & 1.583 & 1.079 & 2.322 \\
\hline CAL & -1.646 & 0.352 & 21.844 & 0.000 & 0.193 & & \\
\hline
\end{tabular}

$B$ partial regression coefficient, $S E$ standardized partial regression coefficient, $O R$ odds ratio, $C I$ confidence interval, $E X P$ exponent with the natural logarithm as base, $X 1$ or $X 2$ stand for the variable

${ }^{a} P<0.05$, indicated to be statistically significant

\section{Discussion}

Because the causes of KD are unclear, it is helpful to conduct a large-scale epidemiologic survey. It is possible to find clues about the etiology and pathogenesis of the disease [15]. The scientific literature on KD since 2000 has been revised and shows that KD has been reported for more than 60 countries since 2004. The incidence rates are highest in Japan, followed by the East Asian countries surrounding Japan such as China, Hong Kong, Taiwan, and Korea. Meanwhile, the incidence rates (or at least the diagnostic rates) are increasing in many countries [26].

The incidence of KD has been increasing in the Jilin Provence of China. Based on the 10-year surveys from 1999 to 2008 in Jilin Provence, the incidence of KD increased from 1.39 per 100,000 children to 11.07 per 100,000 children younger than 5 years from 1999 to 2008, which is much lower than the incidence reported in Japan [17]. Moreover, the incidence of KD in our study also is much lower than that in Beijing, Shanghai, Sichuan Province, Hong Kong, and Taiwan, other developed areas with large population in China [5, 10,11,14, 19,25]. These data together indicate that the incidence of KD among Chinese children has been significantly lower than among Japanese children [17] if these results are truly representative.

The increasing trend also has been found in many other countries and areas such as Thailand, Korea, England, the United States, and Hawaii [6-9, 21]. Thus, the reported incidence of $\mathrm{KD}$ is showing a rising trend throughout the world. However, the true incidence of $\mathrm{KD}$ is unknown because no definite way to diagnose $\mathrm{KD}$ exists. The reported incidence might be increasing because of increased awareness rather than a real increase in the disease. It is worth mentioning that the incidence of $\mathrm{KD}$ in Jilin Provence is similar to that in Israel [3] and Chandigarh of North India [23], which may be caused by a relatively underdeveloped economy or other social reasons in these areas.
Similar to most reports, the age distribution of patients at onset of KD in our survey predominantly involved children younger than 5 years. This age group accounted for $88.73 \%$ of the KD cases [5, 10, 14, 25]. Our results are slightly different from those reported previously in the nation but consistent with the results reported in Japan [16].The peak age of KD onset was 1 year, which is similar to the onset age in Beijing [5].

Male preponderance also was seen in our series. The male-to-female ratio was $1.96: 1$, which is slightly higher than previously reported for most provinces in our country $[5,10,14,25]$.

According to our data, the disease occurred throughout the year, as expressed by a double-peak curve. It occurred more frequently from May to July and November and the least often in February. However, the seasonal distribution of $\mathrm{KD}$ occurrence varied from country to country and even from region to region. The onset of KD occurred more frequently in the summer and spring in Shanghai, Beijing, and Hong Kong [5, 10, 19, 25]. The patient numbers peaked from March to May, and the fewest KD cases occurred during September in the Sichuan province of China [14]. In Taiwan, KD occurred most frequently in the summer and least frequently in the winter [11]. Although the number was highest during the winter months, smaller increases also occurred during the summer months in Japan [17].

In the United States, the number of KD patients was highest in the winter [4]. In Korea, the highest incidence of KD was seen in June, followed by July and May, similar to our first peak [20]. The reasons for the seasonal discrepancy still remain unclear. We speculate that it may be related to climatic conditions, geographic environment, living habits, and the like.

The sequence of main clinical manifestations of KD in Jilin province was similar to that in previous national reports $[5,10,11,14,19,25]$. Fever persisting 5 days or longer was the most frequent clinical manifestation of $\mathrm{KD}$, 
followed by changes in the lips and the oral cavity, changes in peripheral extremities, bilateral conjunctival congestion, rashes, and acute nonpurulent cervical lymphadenopathy. Although not included in the diagnostic criteria of $\mathrm{KD}$, perianal desquamation was seen in $32.9 \%$ of the cases as well as erythema at the Calmette-Guérin Bacillus inoculation site $(1.7 \%)$.

As a systemic vasculitis, KD affects multiple systems. The respiratory system is the most commonly involved system, followed by the digestive system. Involvement can be seen in hematologic system, the urinary system, joints of extremities, and so forth. We found the peak time until medical attention to be $7.58 \pm 4.63$ days. Within 6 days, the patients with a KD diagnosis were fewer because early atypical clinical manifestations of KD sometimes lead to late medical attention as well as delayed diagnosis and treatment. Pediatricians should remain cautious in cases with fever that persists for 5 days or longer.

Coronary artery lesion is of great concern in KD. The CAL occurrence rate varies in different reports. In our survey, CAL was detected in $63.3 \%$ of 553 cases $(49.5 \%$ with ectasia, $13.4 \%$ with stenosis, $0.36 \%$ with aneurysm) during the acute stage. The rate was greater than in other reports $[2,4,5,10,11,14,19,25]$. The higher incidence rate might be due to progress in diagnosing $\mathrm{KD}$, identifying cardiac lesions, and universally applying echocardiography. Fortunately, the proportion of patients with cardiac sequelae has decreased year by year [17]. This improvement might have been caused by IVIG therapy. It was similar to that reported previously for major cardiovascular complications, with no deaths recorded during the acute stage in China [5, 10, 11, 14, 19, 25].

Regarding risk factors of CAL in the patients with KD, this survey found that age and lower serum albumin were the most important risk factors of CAL in KD: the younger the age at onset, the higher the risk of CAL and the higher the incidence of cardiac sequelae. Probably because of delay in diagnosis, only $41 \%$ of infants younger than 6 months were treated with IVIG. Only $14 \%$ of these infants received the therapy during the first 10 days of the disease [22]. Delayed treatment also may have contributed to the development of cardiac sequelae.

Although an early study by Kato et al. [12] suggested that steroids exert a detrimental effect when used as the initial therapy for KD, subsequent studies have shown either no negative effects or a possible benefit. Arguments still exist for the use of steroids. Recent reports by Ganesh et al. [1] have suggested that corticosteroids used in regimens for the initial treatment of $\mathrm{KD}$ decreased rates of retreatment with IVIG. However the addition of corticosteroids to standard therapy did not decrease the incidence of coronary artery aneurysms or adverse events. Tohru et al. [13] reported that prednisolone with IVIG treatment was associated with improvement in clinical and coronary outcomes for patients at high risk for being IVIG nonresponders. In other words, steroids with IVIG in the primary therapy for KD can relieve symptoms quickly and reduce the re-application of IVIG but not the probability of CAL occurrence. It is worth noting that the patients in our data who received steroid treatment more frequently had CAL. It is possible that the severely affected children were treated more readily with steroids, reflecting disease intensity and not some direct effect of steroids themselves on the development of CAL. Nevertheless, the possible effects of steroids themselves on the development of CAL should be not ignored. Careful consideration is required before steroids are used. The use of steroids should possibly be considered only for IVIG nonresponders.

In 1991, Newburger et al. [18] reported that the regimen with $2,000 \mathrm{mg} / \mathrm{kg}$ IVIG was better than the divided dose. Terai and Shulman [24] also reported that the incidence of coronary artery aneurysm was negatively correlated with the IVIG dose: the greater the dose of IVIG, the lower the incidence of CAL. Consequently, IVIG is used more with the regimen of $1,000 \mathrm{mg} / \mathrm{kg}$ once or $1,000 \mathrm{mg} / \mathrm{kg}$ twice in current clinical practice. The reduction in CAL is partly due to this change. In the survey, for $88.7 \%$ of the patients treated with IVIG therapy, the common dose was $400 \mathrm{mg} /$ $\mathrm{kg}$ for 5 days $(39.9 \%)$ or $1,000 \mathrm{mg} / \mathrm{kg}$ twice $(25.7 \%)$. Significant differences were proved between the KD groups with and without administration of IVIG, and CAL was less frequently seen in patients treated with IVIG. Simultaneously, the findings show a significant tendency for an increase in the regimen of $1,000 \mathrm{mg} / \mathrm{kg}$ twice since 2003.

The survey had some limitations. Due to the retrospective nature of the study and the reliance on data from many different centers, with each center using anticoagulant drugs different from standard therapy (intravenous immunoglobulin + aspirin) for patients with acute-phase $\mathrm{KD}$, the treatment effect from every regimen of IVIG could not be proved. The optimal administrative time and dosage of IVIG deserve more observations.

In conclusion, the number of KD patients and the $\mathrm{KD}$ incidence rate are increasing year by year in Jilin Provence. The age and gender distributions are similar to previously reported data. Seasonal distribution differs from that of other reports, and onset of KD occurs more frequently from May to July and November. Age and lower serum albumin are the most important risk factors of CAL in KD. It is possible that patients treated with steroids are more susceptible to CAL.

Acknowledgments The authors thank all of the hospitals and pediatricians participating in this survey of Kawasaki disease (KD). The incidence of KD was calculated by dividing the number of 
patients by the population data obtained from the Statistical Yearbook for Jilin Province.

Open Access This article is distributed under the terms of the Creative Commons Attribution Noncommercial License which permits any noncommercial use, distribution, and reproduction in any medium, provided the original author(s) and source are credited.

\section{References}

1. Athappan G, Gale S, Ponniah T (2009) Corticosteroid therapy for primary treatment of Kawasaki disease: weight of evidence: a meta-analysis and systematic review of the literature. Cardiovasc J Afr 20:233-236

2. Baer AZ, Rubin LG, Shapiro CA et al (2006) Prevalence of coronary artery lesions on the initial echocardiogram in Kawasaki syndrome. Arch Pediatr Adolesc Med 160:686-690

3. Bar-Meir M, Haklai Z, Dor M (2011) Kawasaki disease in Israel. Pediatr Infect Dis J 30:589-592

4. Belay ED, Maddox RA, Holman RC et al (2006) Kawasaki syndrome and risk factors for coronary artery abnormalities: United States, 1994-2003. Pediatr Infect Dis J 25:245-249

5. Du ZD, Zhao D, Du J, Zhang YL, Lin Y, Liu C et al (2007) Epidemiologic study on Kawasaki disease in Beijing from 2000 through 2004. Pediatr Infect Dis J 26:449-451

6. Durongpisitkul K, Sangtawesin C, Khongphatthanayopthin A et al (2006) Epidemiologic study of Kawasaki disease and cases resistant to IVIG therapy in Thailand. Asian Pac J Allergy Immunol 24:27-32

7. Harnden A, Mayon-White R, Perera R et al (2009) Kawasaki disease in England: ethnicity, deprivation, and respiratory pathogens. Pediatr Infect Dis J 28:21-24

8. Holman RC, Belay ED, Christensen KY et al (2010) Hospitalizations for Kawasaki syndrome among children in the United States, 1997-2007. Pediatr Infect Dis J 29:483-488

9. Holman RC, Christensen KY, Belay ED et al (2010) Racial/ ethnic differences in the incidence of Kawasaki syndrome among children in Hawaii. Hawaii Med J 69:194-197

10. Huang G-Y, Ma X, Huang M et al (2006) Epidemiologic pictures of Kawasaki disease in Shanghai from 1998 through 2002. J Epidemiol 16:9-14

11. Huang WC, Huang LM, Chang IS et al (2009) Epidemiologic features of Kawasaki disease in Taiwan, 2003-2006. Pediatrics 123:e401-e405
12. Kato H, Koike S, Yokoyama T (1979) Kawasaki disease: effect of treatment on coronary artery involvement. Pediatrics 63: $175-179$

13. Kobayashi T, Inoue Y, Otani T et al (2009) Risk stratification in the decision to include prednisolone with intravenous immunoglobulin in primary therapy of Kawasaki disease. Pediatr Infect Dis J 28:498-502

14. Li XH, Li XJ, Li H et al (2007) Epidemiological survey of Kawasaki disease in Sichuan Province of China. J Trop Pediatr 54:133-136

15. Nakamura Y, Yanagawa H (2004) The worldwide epidemiology of Kawasaki disease. Prog Ped Cardiol 19:99-108

16. Nakamura $Y$, Yashiro M, Uehara R et al (2008) Increasing incidence of Kawasaki disease in Japan: nationwide survey. Pediatr Int 50:287-290

17. Nakamura Y, Yashiro M, Uehara R et al (2010) Epidemiologic features of Kawasaki disease in Japan: results of the 2007-2008 Nationwide Survey. J Epidemiol 20:302-307

18. Newburger JW, Takahashi M, Beiser AS et al (1991) A single intravenous infusion of gamma globulin as compared with four infusions in the treatment of acute Kawasaki syndrome. N Engl J Med 324:1633-1639

19. Ng YM, Sung RYT, So LY et al (2005) Kawasaki disease in Hong Kong, 1994 to 2000. Hong Kong Med J 11:331-335

20. Park YW, Han JW, Park IS et al (2007) Kawasaki disease in Korea, 2003-2005. Pediatr Infect Dis J 26:821-823

21. Park YW, Han JW, Hong YM et al (2011) Epidemiological features of Kawasaki disease in Korea, 2006-2008. Pediatr Int 53:36-39

22. Rosenfeld EA, Corydon KE, Shulman ST (1995) Kawasaki disease in infants less than one year of age. J Pediatr 126:524-529

23. Singh S, Aulakh R, Bhalla AK et al (2011) Is Kawasaki disease incidence rising in Chandigarh, North India? Arch Dis Child 96:137-140

24. Terai M, Shulman ST (1997) Prevalence of coronary artery abnormalities in Kawasaki disease is highly dependent on gamma globulin dose but independent of salicylate dose. J Pediatr 131:888-893

25. Xiao-jing MA, Cen-yan YU, Min H et al (2010) Epidemiologic features of Kawasaki disease in Shanghai from 2003 through 2007. Chin Med J 123:2629-2634

26. Yanagawa H, Nakamura Y (2008) International comparison of the epidemiology of Kawasaki disease. Nippon Rinsho 66: 237-245 